\title{
"Aprender a nossa língua vernácula": A imigração e educação (rural) no Folha do Oeste (1946-1960)
}

\author{
Rodrigo dos Santos ${ }^{1}$ \\ ${ }^{1}$ Universidade Federal da Fronteira Sul - UFFS. Campus de Laranjeiras do Sul. BR 158, Km 405. Laranjeiras do \\ Sul - PR. Brasil. digao_santos9@hotmail.com
}

RESUMO. Este artigo apresenta uma relação entre Imigração e Educação Escolar no período compreendido entre 1946 e 1960. Esse período é relevante, pois apresenta os imigrantes oriundos da Segunda Guerra Mundial deslocados para vários países, inclusive para o Brasil, habitando os Estados de São Paulo e Paraná. Como fontes, além de discussões bibliográficas, ampara-se no periódico Folha do Oeste. Esse jornal foi produzido em Guarapuava-PR entre 1937 e 1981, sendo o mais longo do Município. A partir dele, procuraram-se matérias e reportagens que apresentam a relação entre educação e imigração. Nos resultados, percebe-se que a imigração era retratada apenas enquanto grupo, destacando neste caso os imigrantes Suábios do Danúbio, e a Educação considerada como rural, porque não considerava os sujeitos, sendo apenas uma questão de Estado para um controle social, promovendo um mínimo de instrução.

Palavras-chave: Educação do Campo, Ensino, Imprensa, Refugiados, Suábios do Danúbio. 


\title{
"Learning Our Vernacular Language": Immigration and education (rural) on Folha do Oeste (1946-1960)
}

\begin{abstract}
This article aims to present a relation between Immigration and School Education in the period between 1946 and 1960. This period is relevant, since it presents the immigrants from World War II who came to several countries, including Brazil, establishing in the States of São Paulo and Paraná. As sources, in addition to bibliographical discussions, it is supported in the periodical Folha do Oeste. This newspaper was produced in Guarapuava-PR between 1937 and 1981, being the longest in the Municipality. We searched for articles and reports that show the relationship between education and immigration. In the results it is noticed that the immigration was portrayed only as a group, highlighting in this case the Suábios do Danúbio immigrants, and the education considered as rural, because it did not consider the subjects, being only a matter of State for a social control, promoting a minimum of instruction.
\end{abstract}

Keywords: Rural Education, Teaching, Press. Refugees, Suábios do Danúbio. 


\section{"Aprender Nuestra lengua vernácula": La inmigración y la educación (rural) en la Folha do Oeste (1946-1960)}

RESUMEN. En este artículo se presenta una relación entre la inmigración y la educación escolar en el período entre 1946 y 1960. Este período es relevante porque muestra los inmigrantes de la Segunda Guerra Mundial que vinieron a países de todo el mundo, incluyendo Brasil, estableciéndose en los estados de Sao Paulo y Paraná. Como fuentes, y discusiones de literatura, soporta a sí misma en el periódico Folha do Oeste. Este periódico se produjo en Guarapuava-PR entre 1937 y 1981, siendo el más largo en la ciudad. Buscaban a los materiales y artículos que presentan la relación entre la educación y la inmigración. En los resultados, es evidente que la inmigración fue interpretado sólo como un grupo, en este caso, destacando los inmigrantes Suábios do Danúbio, y la educación considerada como rural, ya que no tuvo en cuenta el tema, al igual que una cuestión de Estado para el control social, la promoción de un mínimo de instrucciones.

Palabras-clave: Educación Rural, Educación, Prensa, Refugiados, Suábios do Danúbio. 


\section{Introdução}

Esses são, poderíamos dizer, problemas universais e atemporais quando há 'estranhos em nosso meio', aparecendo o tempo todo e assombrando todos os setores da população com uma intensidade e num grau mais ou menos semelhantes (Bauman, 2017, p. 14)

Segundo dados disponíveis pelo Jornal El País (Refluxo..., 2016) em 2015 a Europa acolheu mais de um milhão de refugiados. Desse total, mais de três mil morreram durante a travessia. Ainda com dados do referido jornal em 2016, até o mês de dezembro foram recebidos na Europa mais de trezentos mil imigrantes, destes citados, mais de três mil morreram durante o percurso. O periódico também afirma que no ano de 2017 o número de mortos na travessia procurando condições de refúgio pode ser ainda maior, especialmente depois do atentado em Berlim que proporcionou uma grande aversão aos refugiados por parte da Alemanha, país que possuía políticas mais efetivas de acolhimento a esses sujeitos.

Diante disso, vive-se a maior crise de migração da História. Apesar disso, outros processos de migração também foram sentidos em vários países, especialmente no Brasil. Segundo Bauman (2017, p. 9) a migração em massa é um fenômeno que devido ao "modo de vida moderno" produz "pessoas redundantes", a sobra de pessoas. O excesso de pessoas que são consideradas inúteis, excessivas ou não empregáveis em razão do progresso econômico, ou localmente intoleráveis. Além disso, ocorreram outros movimentos migratórios, especialmente movimentos inversos, como os refugiados da Europa migrando para o Brasil. Os deslocados/refugiados ou apenas imigrantes $^{\mathrm{i}}$ deslocaram por motivos diversos, procurando abrigo durante e depois dos desastres promovidos pela Segunda Guerra Mundial.

$$
\text { Pautando-se na dinâmica }
$$
presente/passado, mas guardando as devidas proporções para evitar anacronismos e presentismos, o presente trabalho apresenta a relação entre esses sujeitos oriundos da Segunda Guerra Mundial e a educação escolar. Essa relação é apresentada a partir do jornal guarapuavano Folha do Oeste. A escolha pelo Paraná não é aleatória. O Estado foi o segundo em acolhimento de imigrantes, sendo ultrapassado apenas pelo Estado de São Paulo. Nesta esteira, Guarapuava se encontra como uma das grandes receptoras de imigrantes do Estado, especialmente pela sua extensão territorial. $\mathrm{O}$ jornal Folha do Oeste também foi significativo, principalmente pela sua duração - mais de quarenta anos - representando os políticos 
da localidade, apontando assuntos internacionais, nacionais e locais.

Para atingir esse objetivo, este trabalho se utiliza de pesquisa documental e bibliográfica. Como documental amparase no periódico Folha do Oeste disponibilizado para o pesquisador pelo Centro de Documentação e Memória de Guarapuava/Arquivo da Universidade Estadual do Centro-Oeste- CEDOC/G.

Com relação à divisão do artigo, essa pesquisa, como forma de situar o leitor, apresenta um histórico das dificuldades de percepção da imigração, sua visualização no Brasil e desenvolve a temática imigração e educação no periódico Folha do Oeste, apresentando avanços de trabalhos na temática ${ }^{\text {ii }}$.

\section{Desenvolvimento}

A migração pode ser definida conforme Santos (1997, p. 6) como “o movimento da população no espaço", sendo esse movimento visualizado de várias formas, de acordo com a percepção de cada pesquisador. São vários os trabalhos que têm como foco a migração, visualizando na sua saída enquanto emigração ou na sua chegada como imigração. Portanto, há uma dificuldade de conceituação do processo migratório, ou do momento como fenômeno migratório. Segundo Nogueira (1991) a migração pode ser estudada considerando a variável tempo e distância. O tempo relativo à pesquisa, sua historicidade e a distância necessária para sua percepção.

Com relação ao período histórico, esse trabalho ampara-se em Shephard (2012) e Judt (2008) que apresentam um tipo específico de imigrante, os imigrantes oriundos da Segunda Guerra Mundial. Antes do fim dessa guerra, milhares de pessoas ficaram longe de suas casas, devido às ações da Alemanha Nazista e da nova divisão mundial. Muitos desses sujeitos preferiam novas moradas que voltar ao seu local de origem, temendo confrontos e represálias. Com isso, a UNRRA (Administração das Nações Unidas para Assistência e Reabilitação), organizações católicas e luteranas, encontraram países que abrigaram esses sujeitos. $\mathrm{O}$ destino preferido dos imigrantes foi os Estados Unidos, seguido pelo Canadá e Argentina. Apesar disso, havia comissões de triagem desses sujeitos e muitos não conseguiam o aceite, sendo direcionados para países como Brasil e Austrália. O Brasil neste contexto, com suas políticas protecionistas em relação aos imigrantes, recebeu uma quantidade pequena de imigrantes se comparada a outros países.

Outro fator relevante aponta para os Estados Brasileiros que abrigaram os 
imigrantes. Santos (2015) destaca que a maioria desses sujeitos vieram para os estados de São Paulo e Paraná, e um número reduzido para os demais. O Estado de São Paulo era atrativo pela industrialização e os imigrantes eram atraídos para o trabalho nas fábricas. Enquanto o Paraná atraía pela agricultura, os imigrantes foram incentivados a colaborar com a carência de alimentos no Estado. Outros imigrantes também foram trabalhar no comércio formal e informal. Os imigrantes vinham até 1949 por via marítima, visto que, a partir desse ano, novas levas começaram a vir por via aérea.

No Paraná o grupo mais numeroso a adentrar suas terras foi o denominado Suábios do Danúbio. De acordo com Elfes (1971) esse grupo tem sua origem juntamente com a migração europeia. Inicialmente, antes da Primeira Guerra Mundial (1914-1918) alguns sujeitos de várias províncias do Reino Alemão, inclusive da Suábia, imigraram para as margens do Rio Danúbio no até então Império Austro-Húngaro. Com o início da Guerra, essas migrações acabaram e, no fim da Guerra, com a desintegração desse Império, esses sujeitos continuaram na Iugoslávia. A localidade desses imigrantes foi invadida pelos soviéticos e posteriormente pelos nazistas durante a Segunda Guerra Mundial (1939-1945).
Diante disso, os Suábios promoveram resistência junto com a população local. Com o final da Segunda Guerra os Suábios foram expulsos, levando apenas o que poderiam carregar nos braços.

O país que acolheu os Suábios foi a Áustria. Entretanto, as instalações dos campos de acolhimento ${ }^{\text {iii }}$ assemelhavamse, conforme Shephard (2012), aos campos de concentração nazistas, por não oferecerem conforto. Por causa disso, organizações internacionais se compadeceram dos Suábios e encontraram uma morada para eles.

Para auxiliar na vinda dos Suábios ao Brasil, uma comissão ${ }^{\text {iv }}$ viabilizou as terras para seu assentamento. Inicialmente, esses sujeitos iriam para o Estado de Goiás, pela grande quantidade de terras devolutas naquele Estado, mas os políticos paranaenses, especialmente o Governador Bento Munhoz e o Secretário de Agricultura Lacerda Werneck, atraíram esses sujeitos para sanar a carência de trigo. Foram ofertadas terras em Goioxim, Clevelâdia, Ponta Grossa e a Fazenda Sobral no Pinhão; mas essas terras, ou eram ácidas ou possuíam pedregulho. No caminho para a localidade de Pinhão, a comissão deparou-se com as terras de Entre Rios e achou esse local ideal para a instalação dos Suábios do Danúbio (Elfes, 
1971). Entretanto, essas terras já possuíam moradores, o que promoveu um processo de desapropriação, venda e permuta que se arrasta até os dias atuais ${ }^{\mathrm{v}}$.

Antes de adentrar-se a discussão sobre imigração e educação, principalmente com os Suábios do Danúbio, é necessário, conforme Luca (2014), conhecer a fonte de pesquisa: o jornal Folha do Oeste. A pesquisadora destaca que alguns elementos devem ser considerados quando se trabalha com fontes periódicas, sendo eles: tomar nota das características da materialidade do periódico; organização das matérias/reportagens; caracterização do grupo responsável pela publicação; colaboradores; problematização da fonte pautada no objeto de pesquisa.

Pautando-se nesses elementos Maria (2011) aponta que o semanário Folha do Oeste surgiu em 1937 e foi extinto em 1981. Foi considerado um dos jornais mais relevantes do município de Guarapuava pela sua temporalidade e inovações como o primeiro da localidade a incorporar imagens. O Folha do Oeste tinha como proprietário Antonio Lustosa de Oliveira, político que exerceu as funções de Prefeito, Deputado Estadual e Federal, Presidente
Estadual da Caixa Econômica Federal, entre outras. Além do referido jornal, Lustosa era dono da Rádio Difusora de Guarapuava-PR e da Gráfica Guairacá. Lustosa era partidário do PSD, por isso, representava a "voz" político partidária desse grupo, ora apoiando e acolhendo o Governo Federal e Estadual nas suas publicações, ora refutando e criticando suas ações.

A pesquisadora Silva (2010) apresenta a trajetória política de Lustosa. Entre algumas curiosidades, aponta o pseudônimo João do Planalto. O político e empresário, quando escrevia textos polêmicos no Folha do Oeste, geralmente, assinava dessa forma. Um nome comum, que poderia ser Paulo, Pedro, Joaquim, Carlos ou Manoel, mas Lustosa optou por João. Já o sobrenome refere-se à localização geográfica da cidade natal de Lustosa, Guarapuava, que se situa no Terceiro Planalto do Estado do Paraná. Na imagem 1 visualiza-se Lustosa como Secretário do Interior e Justiça no jornal Correio da Noite.

Imagem 1- Antonio Lustosa de Oliveira no Correio da Noite em $1^{\circ}$ de junho de 1959. 


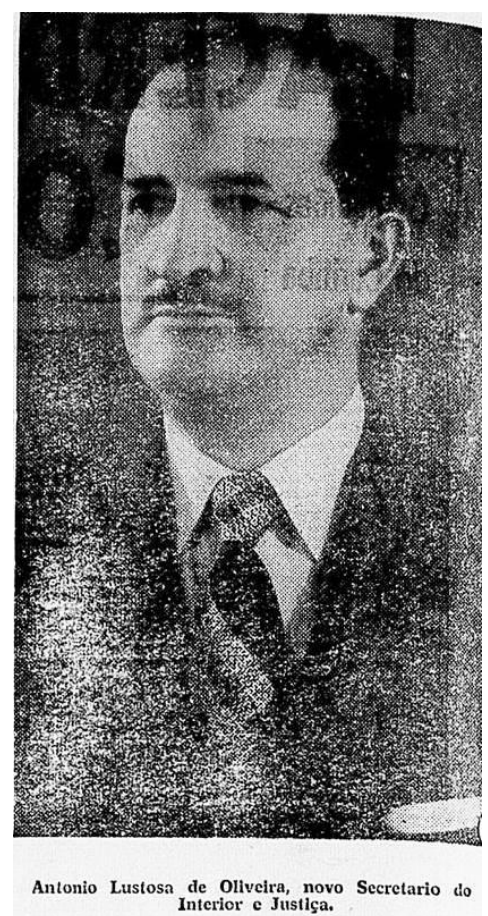

Fonte: Hemeroteca Digital da Biblioteca Nacional

Disponível em: <http://memoria.bn.br/DocReader/cache/5543301623682/I0000014-

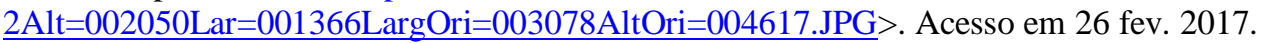

Com relação à materialidade do jornal Folha do Oeste, esse possuía no período da pesquisa (1946-1960) aproximadamente oito páginas, editadas em preto e branco, com algumas imagens, de forma que se utilizassem todos os espaços disponíveis nas páginas, incluindo anúncios, matérias e reportagens. Ele possuía uma extensa circulação, apesar da maioria dos seus exemplares ficarem no Município de Guarapuava e distritos. Circulava na Capital Estadual e Federal por meio de seus representantes. Entretanto, é importante mencionar que o Município de Guarapuava na década de 1950 foi o maior em extensão do Paraná, abrangendo áreas do centro e oeste do Estado. Por isso, o periódico possuía esse nome e se denominava a voz do Oeste do Paraná.

Além disso, é relevante apontar que corriqueiramente o periódico deixava de circular, alegando desculpas aos seus assinantes. Os problemas eram vários: com patrocinadores, assinantes, energia elétrica, aquisição de novos equipamentos, entre outros. Esses problemas, de alguma forma, promoviam ausência de suas edições, apesar de em boa parte de seu período de circulação ser o único semanário da região.

Sobre a problemática escolhida para a pesquisa no período entre 1946 e 1960, são cinquenta e nove matérias/reportagens ${ }^{\mathrm{vi}}$ que, de alguma forma, mencionam a imigração no semanário Folha do Oeste. Apesar disso, 
são poucas as reportagens dedicadas à relação entre imigração e educação escolar.

$\mathrm{O}$ grupo de imigrantes com maior destaque no jornal Folha do Oeste foi o dos Suábios do Danúbio. Gärtner (2014) que analisou os Suábios do Danúbio pela perspectiva da História Ambiental apresenta uma característica desse grupo que merece menção. A autora destaca que diferente de outros grupos imigratórios, a identidade dos Suábios do Danúbio está presente em um rio, o Danúbio, além de uma antiga província do Reino Alemão que uma pequena parcela de sua população é originária, a Suábia.

A imigração dos Suábios do Danúbio repercutiu na imprensa local e nacional. A maioria das matérias no jornal Folha do Oeste no período entre 1946 e 1960 mencionam esse grupo imigratório.

Entre as matérias sobre os Suábios desse jornal, encontra-se uma destacando a quantidade desses imigrantes:

Estão chegando em nossa cidade, os primeiros grupos de emigrantes de raça germânica para a colonização dos campos de Entre Rios.

Sexta-feira ultima, chegaram 220 pessôas, entre as quais, técnicos, para o início da construção de casas de madeira, para que, dentro de um mês, os colonos já estejam alojados em suas casas.

Guarapuava saúda os colonos de além-mar, que vêm auxiliar o desenvolvimento agrário do nosso rincão, desejando-lhes toda sorte de prosperidade (Colono..., 1951, p. 4)
É importante ressaltar que em todas as citações do periódico Folha do Oeste optou-se pela grafia original para facilitar a visualização do discurso da época. Especificamente nesse trecho, o jornal apresenta erroneamente os conceitos de imigração e emigração, pois emigração como mencionado anteriormente, refere-se à observação do migrante em seu local de saída e não no seu lugar de chegada. O correto é imigração.

Apesar disso, a matéria aponta alguns dados sobre os imigrantes Suábios do Danúbio: chegaram em 1951 duzentas e vinte pessoas na primeira leva, posteriormente, vieram outras quantidades para o Município de Guarapuava. A construção das casas foi realizada de madeira, material de abundância em Guarapuava, devido às muitas serrarias que o município possuía; e a construção duraria no máximo um mês.

$\mathrm{Na}$ mesma edição, outra matéria remete aos imigrantes do Danúbio:

É assim que concordaram em ceder as suas terras à Cooperativa Agrária, numa demonstração de altiloquente grandeza patriotica, que bem exteriorisa o desejo de progresso que os anima, quando está em jogo o bem coletivo da comunidade Guarapuava. Não quizeram os descendentes dos primitivos povoadores do oeste paranaense, imitar o gesto desassombrado do audaz cacique Guairacá, quando enfrentando os invasores dos seus domínios, conclamavam as suas aguerridas 
tribus, com o seu grito de guerra: 'Essa terra tem dono'! Preferiram os fazendeiros de Entre-Rios abrir os braços e acolher os seus irmãos da velha e conturbada Europa, com um amplexo de solidariedade cristã, ensejando-lhes em terras brasileiras, o direito de paz, de liberdade e de trabalho construtivo, em benefício da prosperidade do Paraná e do Brasil (Essa Terra tem dono!, 1951, p. 1).

A matéria em questão aponta o conflito decorrente da vinda dos imigrantes e os sujeitos que já habitavam aquela localidade, especialmente os fazendeiros. A discussão expressa na matéria remete a uma questão indígena do desbravamento pelos "brancos" dos campos de Guarapuava no século XIX, comparando a imigração dos Suábios do Danúbio com a resistência indígena. Enquanto na vinda dos imigrantes os fazendeiros deixaram suas casas, no século XIX os indígenas lutaram pela permanência nelas.

Uma das matérias que comenta a relação educação e imigração foi publicada em 22 de novembro de 1953, sendo uma reprodução do discurso do Deputado Antonio Lustosa de Oliveira de 11 de novembro na Assembleia do Paraná.

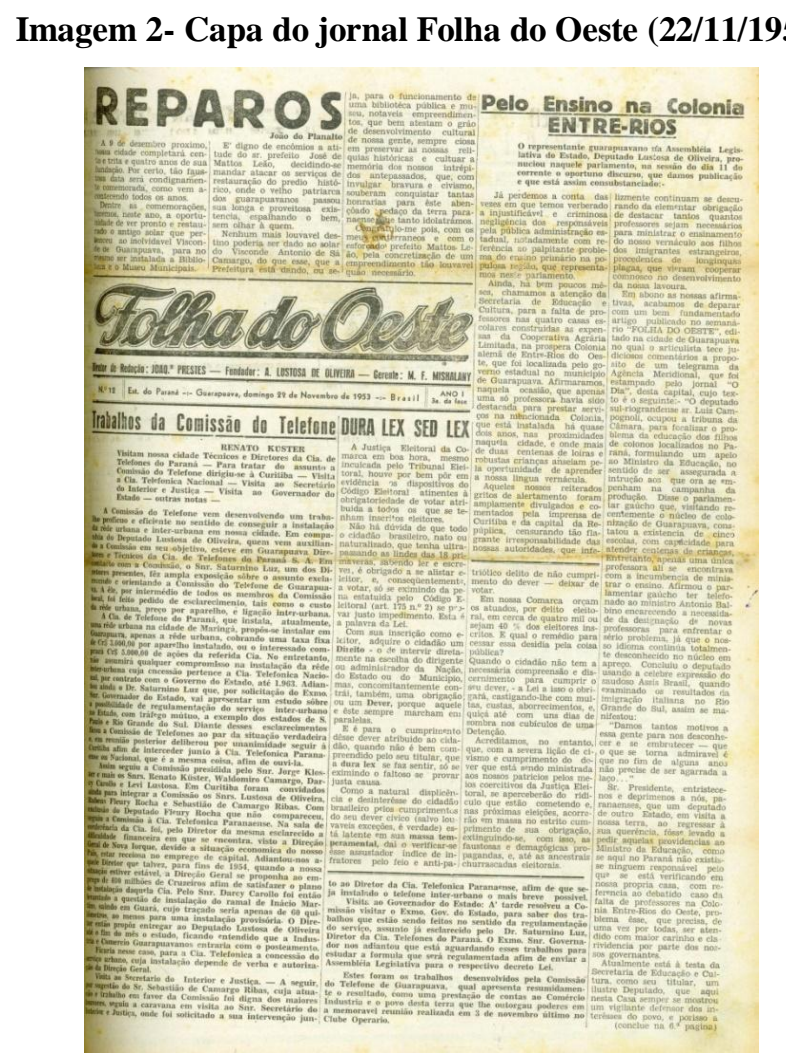

Fonte: CEDOC/G. 
O início da matéria (Imagem 2) aponta, de forma geral, o descaso do Governo do Estado com o Ensino Primário:

Já perdemos a conta das vezes que temos verberado a injustificável e criminosa negligência dos responsáveis pela pública administração estadual, notadamente com referência ao palpitante problema do ensino primário na populosa região, que representamos neste parlamento (Pelo Ensino..., 1953, p. 1).

Destaca-se, neste trecho, que o descaso com o ensino no Paraná é corriqueiro, principalmente na região central e oeste do Estado. Segundo Barreiro (2007), por essa carência educacional a iniciativa da construção de escolas no meio rural nas décadas de 1930, 1940 e 1950 era da própria comunidade, pois as políticas de educação estatais ficavam restritas principalmente a Curitiba. Essas escolas, construídas pelos proprietários das fazendas, possuíam características da Educação Rural com a importação de modelos da cidade e atendiam a momentos considerados de crise na área rural como o êxodo rural, analfabetismo e modernização da agricultura.

No segundo parágrafo da matéria se apresenta o problema, levantado por Lustosa, no ensino para os imigrantes:
Ainda, há bem poucos mêses, chamamos a tenção da Secretaria de Educação e cultura, para a falta de professores nas quatro casas escolares construídas as expensas da Cooperativa Agrária Limitada, na prospera Colonia alemã de EntreRios do Oestes, que foi localizada pelo governo estadual no município de Guarapuava. Afirmaramos, naquela ocasião, que apenas uma só professora havia sido destacada para prestar serviço na menciona Colonia, que está instalada há quase dois anos, nas proximidades naquela cidade, e onde mais de duas centenas de loiras e robustas crianças anseiam pela oportunidade de aprender a nossa língua vernácula (Pelo Ensino..., 1953, p. 1).

O problema em questão é a ausência de professores para ensinar a língua nacional, pois os governantes acreditavam que o ensino, mesmo que para o imigrante oriundo de regiões europeias, deveria ser pronunciado em língua portuguesa, o que foi resolvido em 1958 com a nomeação de um novo professor ${ }^{\text {viii }}$.

Outro fator relevante apontado por esse trecho é a criação de quatro casas escolares construídas com recursos da cooperativa que representa os Suábios. Conforme Stein (2011), a relação dos Suábios com a educação é antiga, pois eles ficaram alojados em uma escola no centro do Município de Guarapuava até que conseguissem construir suas casas em 1951; e hoje a cooperativa mantém um colégio para seus associados ${ }^{\mathrm{ix}}$. 
A obrigatoriedade dos governantes para o ensino aos imigrantes também é destacado na matéria:

... nossas autoridades, infelizmente continuam se descurando da elementar obrigação de destacar tantos quantos professores sejam necessários para ministrar o ensinamento do nosso vernáculo aos filhos dos imigrantes estrangeiros procedentes de longínquas plagas" (Pelo Ensino..., 1953, p. 1).

Além disso, a matéria faz referência à outra matéria que pediu providências ao Governo Federal:

Em abono as nossas afirmativas, acabamos de deparar como um bem fundamentado artigo publicado no semanário 'FOLHA DO OESTE', editado na cidade de Guarapuava no qual o articulista tece judiciosos comentários a proposito de um telegrama da Agência Meridional, que foi estampado no jornal 'O Dia', desta capital (Pelo Ensino..., 1953, p. 1)

A matéria intitulada Quisito Social ${ }^{\mathrm{x}}$ encontra-se na edição de 25 de outubro de 1953:

Um atilado parlamentar gaúcho, deputado Luiz Campagnolli - em recente visita à Cooperativa Agricola Jordão, séde em Entre Rios, concluiu, de plano, em discurso na Câmara Federal, que os nossos foros de brasilidade estão sendo criminosamente comprometidos no evoluir daquele nucleo teotônico em terras brasileiras, isso porque a nossa língua e nossa Historia, são ali descuradas (Quisito..., 1953, p.1).
A matéria em questão apresenta referência à outra matéria ${ }^{\mathrm{xi}}$, destacando que o Deputado Federal compactua com o ensino em língua nacional para os imigrantes e o mesmo deveria ocorrer em Entre Rios. Caso não ocorresse, se acreditava que estariam destruindo o idioma e a história do país.

Outro trecho da matéria destaca como estaria o ambiente em Entre Rios: “Afóra o ar e o sol, em sentido subjetivo, porque o direito de propriedade, ali, é dos imigrantes, - nada mais lembra o Brasil. Desde o pó dos adubos que encrementam o solo até o ecoar dos hinos litúrgicos ... tudo recorda o estrangeiro". (Quisito..., 1953, p. 1). Ou seja, o ambiente dos imigrantes lembraria aspectos europeus e não terras brasileiras.

Pelo fragmento, visualiza-se que o receio trazido pelo imigrante é do estranho, do diferente. Os pesquisadores Santos, Almeida e Schörner (2015) apontam que o imigrante advindo da Segunda Guerra Mundial era considerado um alienígena, pois representava um indivíduo com costumes e crenças diferentes dos nacionais, sendo comparados pelos periódicos da época com objetos estrangeiros, como máquinas de costuras. Os nacionais acreditavam que, ao acolher os imigrantes, realizavam uma benfeitoria, 
e os imigrantes tinham como obrigação retribuir isso.

O medo e a ansiedade causada pelo estranho, pelo diferente, também é destacado por Bauman (2017, p. 13): "estranhos [os imigrantes] tendem a causar ansiedade por serem 'diferentes"'. Uma questão é não gostar do vizinho ou do colega do trabalho, mas se habita o mesmo espaço, convive cotidianamente com as manias, sabe suas ações e reações. Outra questão é conviver com o diferente, com aquele que não se conhece, que não é previsível, com outra forma de vestir, comer e se locomover, diferente dos que habitam aquele espaço. “... a ignorância quanto a como proceder, como enfrentar uma situação que não produzimos nem controlamos, é uma importante causa de ansiedade e medo". (Bauman, 2017, p. 1). $\mathrm{O}$ autor aponta que ocorre uma ignorância de como proceder na tentativa de controlar a situação.

Esses sujeitos do pós-segunda guerra, devido a esse medo e ansiedade, eram estigmatizados ${ }^{\mathrm{xii}}$, pois recebiam, conforme Peres (1997), denominações pejorativas como: neuróticos de guerra, psicopatas encubados, mau elemento, indesejáveis, entre outros. Além disso, Stein (2011) aponta que as denominações germânica ou imigrantes alemães também eram evitadas, especialmente pelos periódicos, para não associar os imigrantes ao nazismo. Nesse sentido, se preferia denominações como imigrantes europeus, alienígenas, apátridas, suíços e camponeses.

Por fim, a matéria apresenta uma comparação do Estado do Paraná com Santa Catarina,

E se assim não fizermos, criar-seão em nosso Territorio como outrora em Santa Catarina, verdadeiro quistos raciais ... $\quad$ É preciso que as autoreidades do ensino, - os Inspetores Estaduais ou delegados de Ensino visitem, aos menos uma vez por ano aquele nucleo de imigrantes, para se capacitarem do que por lá ocorre ... (Quisito..., 1953, p.1)

O trecho cobra das autoridades, dos Inspetores Estaduais e Delegados Educacionais, para visitarem no mínimo uma vez por ano a Colônia Entre Rios e tomarem providências com relação à contratação de professores e que o ensino seja realizado em língua nacional. A pesquisadora Peres (1997), respaldada nas matérias da Revista de Imigração e Colonização, destaca que a escola tinha como função um controle do imigrante, pois as autoridades acreditavam que ensinando em língua nacional seria mais fácil a assimilação destes sujeitos com a cultura brasileira.

Além disso, Peres (1997) também aponta que, junto com o ensino em língua portuguesa, os pensadores da época 
acreditavam que os imigrantes deveriam aprender história, geografia e o espírito de associação. Com isso, os imigrantes se preparariam para a naturalização, vista como renúncia e conversão. Essa conversão, patrocinada pelo Governo Brasileiro, seria uma renúncia de todos os erros comentidos do passado estrangeiro.

As providências também são questionadas a partir da legislação na primeira matéria do Folha do Oeste aqui apresentada:

Esperamos pois, que desta feita, sejam tomadas energicas providencias para sanar uma falha ... na conformidade com o que estatue o art. 168 da Constituição da República onde se declara que 'o ensino primário é obrigatorio e só será dado na lingua nacional" (Pelo Ensino..., 1953, p. 6).

Essa hostilidade ao imigrante com receio de criação de grupos isolados, tratando-os com acusações, calúnias e depreciações aponta para uma desumanização dos migrantes:

... A desumanização abre caminho à exclusão da categoria de seres humanos legítimos, portadores de direitos, e leva, com nefastas consequências, à passagem do tema da migração da esfera da ética para a das ameaças à segurança, prevenção e punição do crime, criminalidade, defesa da ordem e, de modo geral, do estado de emergência comumente associado à ameaça de agressão e hostilidades... (Bauman, 2017, p. 84).

Com isso, a imigração se transforma num gigantesco confronto entre nacionais e internacionais, legalizado pelas políticas de migração, que afetam as muitas esferas da vida humana. $\mathrm{O}$ imigrante se torna um risco à segurança nacional, sendo passível de criminalização.

Pelas percepções apontadas pelas matérias, esse tipo de educação preconceituosa destinada aos sujeitos que habitam a zona rural é a Educação Rural, que mostra o sujeito do campo como atrasado $^{\text {xiii }}$. Neste contexto da Educação Rural que se criou na década de 1950, a Campanha Nacional de Educação Rural (CNER) e o Serviço Social Rural (SSR) desdobrando-se na Campanha de Educação de Adultos e nas Missões Rurais de Educação de Adultos que, como aponta Leite (2002), tinham como objetivo melhorar a vida dos sujeitos que habitavam a área rural, possivelmente também os imigrantes.

Imagem 3 - Campanha Nacional de Educação de Adultos (Folha do Oeste- 23/03/1958). 


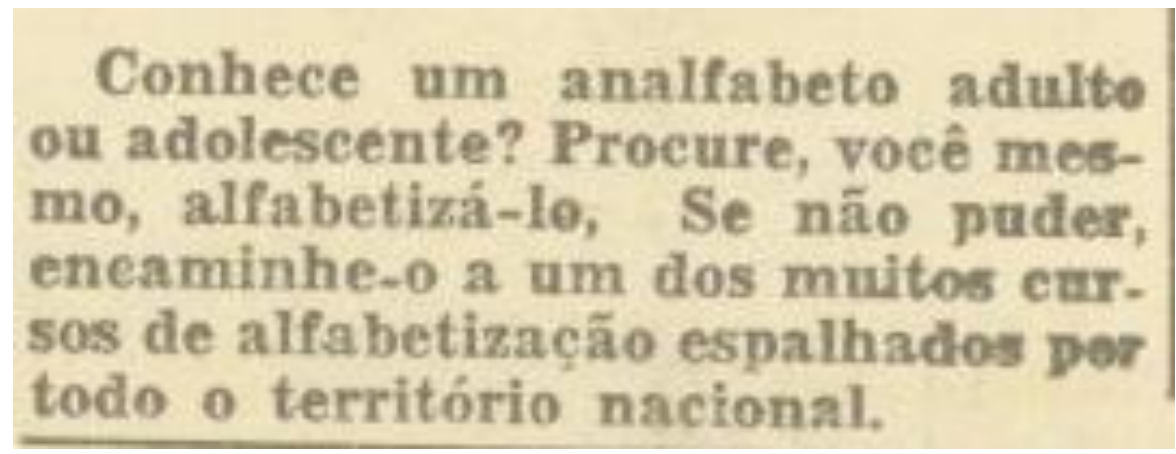

Fonte: CEDOC/G.

O movimento promovido pela CNER também pode ser visualizada no jornal Folha do Oeste com pequenos avisos entre matérias e reportagens durante a década de 1950 (Imagem 3). Além disso, “... a CNER ao realizar seu trabalho educativo, desconsiderou as contradições naturais dos grupos campesinos, ou mesmo seus elementos integrativos, quer políticos, sociais ou culturais". (Leite, 2002, p. 37). Essas campanhas em nada consideravam os sujeitos do campo, apontando estes como atrasados.

Os pesquisadores Caldart (2009) e Leite (2002) apresentam características da Educação do Campo e da Educação Rural. Percebe-se que a Educação Rural foi relevante para a década de 1950 para reduzir os índices de analfabetismo na zona rural, forma de controle social, ou mesmo, um mínimo de instrução. No entanto, esse tipo educacional não lembra a Educação do Campo, da classe trabalhadora que prioriza a participação de todos os sujeitos do campo no seu processo de construção de conhecimento.

\section{Considerações finais}

Neste artigo se percebe que o processo migratório é complexo, dependendo especialmente de sua visualização. Neste caso específico, se visualizou a partir do seu local de chegada, a imigração. Além disso, utilizaram-se como fonte de pesquisa as matérias do jornal Folha do Oeste, do período compreendido entre 1946 e 1960, em que tiveram como imigrantes alguns sujeitos da Segunda Guerra Mundial.

Nesta esteira, aliou-se a questão da educação, respondendo ao objetivo proposto sobre como foi visualizado a imigração e a educação escolar no referido periódico. Como resultado, se observa que mesmo que o jornal tivesse algum tipo de preocupação com a imigração, essa era restrita, só com grupos numerosos, e quando se pensava a educação, era 
destinada ao imigrante como um meio de controle social.

$\mathrm{Na}$ imigração como questão nacional, as matérias destacam que o imigrante necessitava de um ensino em língua nacional, ou seja, língua nativa, vernácula; o português. E se promovessem o ensino, as autoridades da época acreditavam que os imigrantes construiriam grupos isolados, como fizeram em Santa Catarina, uma alusão as Colônias de imigrantes neste Estado que depois se transformaram em Municípios na atualidade. Por isso, tão necessário esse ensino, como um problema nacional a ser recebido. Uma das matérias justifica isso com um artigo até então da Constituição Federal do período.

Outro fator relevante refere-se ao fato que um deputado, não exatamente paranaense, sentiu-se incomodado com a ausência de ensino no Estado do Paraná para os imigrantes em língua nacional e pronunciou tanto para a imprensa nacional como para o Governo Federal, cobrando a resolução desta questão. Essa cobrança surtiu efeito, sendo nomeado um novo professor para a localidade. Mesmo assim, das quatro casas escolares, duas ficaram com professores ensinando em língua estrangeira.

Por fim, igualmente merece destaque a modalidade de ensino Educação Rural que em nada lembra a Educação do Campo promovida pelos movimentos sociais na atualidade. A Educação Rural apontada pelo jornal Folha do Oeste pautava num mínimo de instrução para os sujeitos habitantes da área rural, buscando reduzir os índices de analfabetismo e controlar a migração campo-cidade.

\section{Referências}

Barreiro, E. (2007). Políticas Educacionais e escolas rurais no Paraná 1930-2005. (Dissertação de Mestrado). Universidade Estadual de Maringá.

Bauman, Z. (2017). Estranhos a nossa porta. Rio de Janeiro: Zahar.

Caldart, R. S. (2009). Educação do Campo: Notas para uma análise de percurso. Trab. Educ. Saúde, 7(1), 35-64. Disponível em:< http://www.scielo.br/pdf/tes/v7n1/03.pdf $>$. Acesso em: 02 jan. 2017.

Colonos para Guarapuava (1951, 10 de junho). Folha do Oeste, p. 4.

Desconhecem os Colonos de Guarapuava o nosso idioma (1953, 25 de outubro). Folha do oeste, p. 6.

Elfes, A. (1971). Suábios no Paraná. Curitiba: [s. n.].

Errata. (1953, 25 de outubro). Folha do Oeste. p. 6.

Gärtner, M. (2014). Alguns elementos para a construção de uma História Ambiental do processo de "europeização" da paisagem do Distrito de Entre Rios, Guarapuava, Paraná. (Dissertação de 
Mestrado). Universidade Estadual do Centro-Oeste.

Judt, T. (2008). Pós Guerra: uma história da Europa desde 1945. Rio de Janeiro: Objetiva.

Leite, S. C. (2002) Escola Rural: urbanização e políticas educacionais. São Paulo: Cortez.

Luca, T. R. (2014). História dos, nos e por meio dos periódicos. In Pinsky, C. B. Fontes Históricas. São Paulo: Contexto.

Maria, G. V. (2011). Crônicas da alta sociedade: Discursos, representações $\mathrm{e}$ cotidiano nas colunas sociais do jornal Folha do Oeste (Guarapuava, PR, 19591964). (Tese de Doutorado). Universidade Estadual Paulista Júlio de Mesquita Filho.

Nogueira, O. J. O (1991). Migrações internas: tentativas de buscar uma teoria. Análise e Conjuntura. 6(1), 38-47. Disponível em: < http://www.repositorio.fjp.mg.gov.br/bitstr eam/123456789/75/1/Migra\%C3\%A7\%C3 \%B5es\%20Internas\%20tentativas\%20de\% 20se\%20buscar\%20uma\%20teoria.pdf>.

Acesso em: 28 dez. 2016.

Novas professoras nomeadas para Guarapuava. (1958, 17 de agosto) Folha do Oeste. p. 7.

Organização Internacional para as Migrações-OIM (2009). Direito internacional da migração: Glossário sobre migração. Genebra: OIM. Disponível em: < http://www.acidi.gov.pt/_cf/102363> Acesso em: 17 fev. 2014.

Pelo Ensino na Colonia Entre Rios (1953, 22 de novembro) Folha do Oeste. p. 1.

Peres, E. P. (1997). "Proverbial Hospitalidade"? A Revista de Imigração e Colonização e o discurso oficial sobre o imigrante (1945-1955). Acervo, 10(2), 55-
70. Disponível em: < http://revista.arquivonacional.gov.br/index. php/revistaacervo/article/view/254/254> . Acesso em: 11 jan. 2017.

Quisito Social. (1953, 25 de outubro). Folha do Oeste. p.1.

Rabaça, C. A., \& Barbosa, G. G. (2014). Dicionário essencial de comunicação. São Paulo: Lexikon.

Refluxo solidário na EU. (2016, 23 de dezembro). El País. [Online]. Editorial. Disponível em: http://brasil.elpais.com/brasil/2016/12/22/o pinion/1482434415_511282.html $>$. Acesso em 28 dez. 2016.

Santos, R. (2015). Discursos sobre imigração no jornal Folha do Oeste Guarapuava, Paraná (1946-1960) (Dissertação de Mestrado). Universidade Estadual do Centro Oeste. Disponível em:< http://www2.unicentro.br/ppgh/files/2015/ 07/Disserta o de Rodrigo dos Santos 56 2a8c0985c01.pdf>. Acesso em: 6 jun. 2016.

Santos, R. (2016). A imigração dos Suábios do Danúbio e as discussões pelas terras de Entre Rios, Guarapuava, Paraná. Revista Sociais e Humanas, 29(1), 08-18. Disponível em: $<$ https://periodicos.ufsm.br/sociaisehuman as/article/view/17645>. Acesso em: 29 dez. 2016.

Santos, R., \& Volupca, T. (2015). O diálogo entre Educação Rural e Migração em Guarapuava (1920-1950). In Mello, A (Org.). Educação e sociedade em Guarapuava: cenários de pesquisa (pp. 159-170). Curitiba, PR: CRV.

Santos, R., \& Volupca, T. (2014) Educação rural e migração: a tentativa do diálogo. Luminária, 16(2). Disponível em: < http://periodicos.unespar.edu.br/index.php/ 
luminaria/article/view/336/280>. Acesso em: 28 dez. 2016.

Santos, R. B. (1997). Migração no Brasil. São Paulo: Scipione.

Santos, R., Almeida, M. L., \& Schörner, A. (2015). Os alienígenas do pós-guerra: percepções sobre os displaced persons entre 1945 e 1960. In Anais do V Colóquio Nacional Cultura e Poder (pp. 268-280). Campo Mourão, PR. Disponível em: < http://www.fecilcam.br/culturaepoder/wpcontent/uploads/2015/09/Anais-

VColoquio.pdf >. Acesso em 11 fev. 2017.

i O refugiado, ao entrar em uma nova Pátria, perde sua condição de refúgio, sendo reconhecido como cidadão do país. Apesar disso, não perde o estigma de imigrante (Santos, 2015).

ii Sobre Educação e (I) migração publicouse: Santos e Volupca $(2014 ; 2015)$.

iii Também denominados por Shephard (2012) de Campo de Refugiados. Optou-se pela primeira expressão, pois nesses campos encontravam deslocados, refugiados, colaboracionistas, apátridas (sujeitos sem Pátria).

iv A instituição era a Caritas Suíssa para Auxílio Suíço para a Europa e a comissão foi composta por dois padres e um engenheiro (Gärtner, 2014, p. 37).

v As discussões sobre as Terras de Entre Rios foram problematizadas em Santos (2016).

vi Entende-se como matéria qualquer escrito jornalístico e reportagem como um escrito mais elaborado que necessita da ida do repórter a campo, além de todas as técnicas jornalísticas como a apuração e confrontação de dados (Rabaça \& Barbosa, 2014).

vii Optou-se pela grafia original das fontes em suas citações.

viii Diferente da proposta da matéria de 1953, foi nomeado para a Colônia Entre Rios um professor e não uma professora, como consta na
Shephard, B. (2012). A longa estrada para casa: restabelecendo o cotidiano na Europa devastada pela guerra. São Paulo: Paz e Terra.

Silva, W. P. (2010). De Lustosa a João do Planalto: a Arte Política na Cidade de Guarapuava (1930- 1970). Guarapuava: UNICENTRO.

Stein, M. N. (2011). O oitavo dia: produção de Sentidos Identitários na Colônia Entre Rios - PR (segunda metade do século $X X)$. Guarapuava: UNICENTRO.

matéria de 17 de Agosto de 1958 (Novas Professoras..., 1958, p. 7).

ix Maiores informações sobre o Colégio http://www.colegioimperatriz.net.br/>.

x Uma errata publicada na mesma edição aponta que a matéria deveria ser intitulada Quisto Racial. (Errata, 1953, p. 6).

xi O discurso do Deputado foi republicado do "O Dia" nesta mesma edição (Desconhecem..., 1953, p. 6).

xii Entende-se como estigma a crença que uma característica de uma pessoa ou grupo que se torna seus portadores por essência é diferente dos demais (Bauman, 2017, p. 44).

xiii É relevante frisar que como afirma Caldart (2009, p. 40) "Educação do campo não é Educação rural", apesar de ambas serem destinadas aos sujeitos que habitam a zona rural. A Educação do Campo é datada da década de 1990.

Recebido em: 13/02/2017 Aprovado em: 25/02/2017 Publicado em: 19/04/2017 
Como citar este artigo / How to cite this article / Como citar este artículo:

APA:

Santos, R. (2017). "Aprender a nossa língua vernácula": A imigração e educação (rural) no Folha do Oeste (1946-1960). Rev. Bras. Educ. Camp., 2(1), 275-293. DOI: http://dx.doi.org/10.20873/uft.2525$\underline{4863.2017 \mathrm{v} 2 \mathrm{n} 1 \mathrm{p} 275}$

ABNT:

SANTOS, R. "Aprender a nossa língua vernácula": A imigração e educação (rural) no Folha do Oeste (1946-1960). Rev. Bras. Educ. Camp., Tocantinópolis, v. 2, n. 1, p. 275-293, 2017. DOI: http://dx.doi.org/10.20873/uft.2525$\underline{4863.2017 \mathrm{v} 2 \mathrm{n} 1 \mathrm{p} 275}$ 